\title{
The Promotion of Teenagers' Physical Fitness and Health from the Perspective of Comprehensive Development of Human Beings
}

\author{
Yong $\mathrm{Yu}$ \\ Collaborative Innovation Center of Assessment toward Basic Education Quality \\ Beijing Normal University \\ Beijing, China \\ yongyu@bnu.edu.cn
}

\begin{abstract}
National physical fitness monitoring results show that the physical quality of teenagers declines for more than ten years in China. Physical health level of students is the short board of comprehensive quality of teenagers' all-round development. The state and society are aware of the importance of promoting teenagers' physical fitness and health. The strengthening of physical education and promote students' physical and mental health and overall development policy regulations have been issued. Comprehensive development of the Marx doctrine as the main line, the physical health of teenagers is strived to complete in this short board. To help teenagers train sports interest, develop a lifelong habit of physical exercise, bring up healthy lifestyles, grasp the movement technology, promote the rule and cooperation consciousness and determination of the quality of physical education and health, we must improve teenagers' sports literacy and comprehensive development.
\end{abstract}

Keywords-comprehensive development; physical fitness and health; teenagers; promotion

\section{INTRODUCTION}

School physical education is the weak link of the whole education. It exist some problems, such as the lack of awareness of the importance of school physical education, physical education and extracurricular activities not being guaranteed, the shortage of teachers, the lack of facilities and so on. School physical education evaluation mechanism should be set up. The physical health level of students is still the obvious short board [1]. The country needs to further promote the reform and development of school physical education, to improve students' physical and mental health, to promote the comprehensive development of teenagers.

\section{MARX'S CONCEPT OF COMPREHENSIVE DEVELOPMENT}

\section{A. The connotation of the person's comprehensive development}

As the existence of spiritual life, the comprehensive development of human beings must be based on the material and spiritual enrichment. Marx in the Outline of Feuerbach attributes to the nature of the sum of all social relations, the social nature of the first person to enhance the height. Marx believes that the essence of human beings is not innate, but the product of the shaping of acquired life practice [2]. That is, only the social development of talent is the real meaning of "people". The comprehensive development of human beings is built on the material needs and spiritual needs of the dialectical unity, personal development and social development is the dialectical unity, full freedom and social control, and on the dialectical unity of self-realization and social interests of the dialectical unity of the four, is a dynamic process with comprehensive and the complexity of the individual and others, such as social, natural interaction with gradually deepening development, its essence is historical, concrete and development.

The comprehensive development has always been a variety of interpretation, on the whole can be divided into functions, get rid of the shackles, potential release and profound thinking four representative views, but in the basic kernel means the liberation of humanity and sublimation. The comprehensive development of human beings is highly concerned about the development of society, because the comprehensive development of individuals is not only related to the individual, but also to the society. Society is a collection of people whose nature and state are influenced and restricted by the state of the individual. The historic decision closely linked to the overall development of individual development and society, must reflect the internal needs of the individual and the society's progress and development, growth and evolution of the individual and society, highlighting the social development achievements. Therefore, the comprehensive development of human beings, in a certain sense, is an effective way to promote the development of society, even if the progress and development of society.

\section{B. The performance of the comprehensive development}

The comprehensive development of human being includes eight dimensions: ability, quality, needs, personality, ideological quality, relationship, ecology and personality. The dimensions of the emphasis on individual's ability and potential emphasize quality. Dimensions of qualities in full and comprehensive development needs emphasize the need to satisfy the dimensions according to the process of personal style. Personality dimension refers to individual freedom. Quality refers to the ideological quality, moral level, aesthetic ability and artistic accomplishment, multi-dimensional 
development, and culture noble character. The relationship dimension refers to include personal relationships with other people, individual and collective relationship, the relation between man and society and man and the heart of the relationship. The ecological dimension describes comprehensively the relationship between man and nature is not only dependent on the transcendence. Personality is the ideal personality formation and independent personality, the highest realm overall development of human beings. Specifically, the comprehensive development of people is the coordination in such aspects as economy, politics, and culture, to improve performance in physical strength, intelligence, personality, emotion, creativity, interpersonal interaction, social adaptation and other aspects. It is the individual to participate in social activities, the realization of personal value and social value of the degree of comprehensive improvement and coordinated development.

\section{RELEVANT POLICIES AND REGULATIONS ON THE PROMOTION OF YOUTH PHYSICAL FITNESS}

According to the National Long-term Education Reform and Development Plan (2010-2020), school physical education set "to exercise every day, healthy growth, lifelong benefit" as the goal, requirements to ensure that students exercise for an hour every day. We pay attention to their aptitude and happy participation, and pay attention to sports skills training to students' basic physical exercise habits, to improve sports skills and physical health level, significantly to enhance the awareness of the rules, the spirit of cooperation and willpower, to improve students' physical quality and students personality quality. We play sports of socialist core values and promote the comprehensive role of quality education in the cultivation and practice of society, to cultivate comprehensive development of teenagers. These are the true embodiment of Marx's concept of comprehensive development in school physical education.

The general office of the State Council issued the Strengthening of School Physical Education to Promote Physical and Mental Health of Students Comprehensive Development of Opinions (GUO Ban Fad 2016 No. 27). The Opinions in the fifth part are "to strengthen the evaluation of monitoring, to promote the healthy development of school sports, through the improvement of examination evaluation method" and "strengthening teaching quality monitoring of sports", the two paragraphs describe the State Council to strengthen the school physical education for promoting the comprehensive development of students' physical and mental health advice. The Opinions stress that the assessment of physical education curriculum should highlight the process management, a comprehensive evaluation from the students' attendance, classroom performance, health knowledge, sports skills, physical health, and participate in extracurricular exercise activities in seven aspects. In primary and secondary school physical education, they focus that students' participating in sports activities, students' physical health status and sports skill level in middle and high school students are brought into academic proficiency test and comprehensive quality evaluation system. To strengthen the quality of physical education teaching monitoring, we must establish the primary and secondary school physical education curriculum implementation monitoring system, and regularly carry out physical education curriculum of national basic education quality monitoring. We must establish and improve the students' physical health records, strict implementation of the National Student Physical Health Standards, and be seen as an important basis for the construction of school sports evaluation mechanism.

For the implementation of the National Fitness Strategy and the Comprehensive Well-off Society, the State Council launched the National Fitness Program (2016-2020), to highlight the youth as a focus group to implement the national fitness program, to promote youth sports activities, to improve the physical fitness of young people [3]. To strengthen the school sports education, we must take promoting youth sports literacy and developing healthy behavior as important parts of school education, to ensure students in school sports venues and training time. We must bring the physical health level of students into the evaluation system, to strengthen the school sports work performance evaluation and administrative accountability. The full implementation the Plan of Promoting Youth Sports Activities, actively plays a leading role in the demonstration of Sunshine Sports Conference youth sports brand activities, enhancing physical fitness, so that young people master sports skills, training interest, forming a good habit of lifelong physical fitness.

To build Well-off Society in the decisive stage and promote comprehensive, harmonious and sustainable development of China's physical education, the state formulates sports development plan of 13th Five-Year and highlights to speed up the development of youth sports activities to promote the implementation of the plan [4]. It carries out a wide range of diverse youth public sports activities and sports skills the promotion of youth training, physical exercise habits, to master more than one sports skills. To explore the cultivation of youth sports instructor team, to promote the construction of youth sports volunteer service system, and improve the evaluation mechanism. Planning requirements and regulations are in line with the overall development of the people as the goal, to strengthen the promotion of young people's physical health.

\section{COMPREHENSIVE DEVELOPMENT FROM THE PERSPECTIVE OF TEENAGERS' PHYSICAL EDUCATION}

Physical education is one of the most important courses in primary and secondary schools, and its distinctive practical and flexible forms of organization in the classroom have been paid great attention in the world. All countries identify it as an excellent course of social development and social training. The curriculum includes a lot of interpersonal communication, personality, habits, values, coping style and social setting, content of human and nature and society along the way. Promoting the individual's social development through the reasonable physical education curriculum is undoubtedly the advanced goal of physical education curriculum, and the highest embodiment of physical education curriculum. There is no training effect of physical exercise on team organization ability, interpersonal relationship, individual ability and leadership of the doubt. It will be of different age and sex, personality and cultural background of the individual 
connected together through the internal communication organization members to broaden their horizons and increase social support and psychological benefits such as a sense of belonging.

The reasonable way of physical education courses create specific practical situations to help students find the way of getting along with people, practical manners and etiquette, learn interpersonal skills, so as to promote the comprehensive improvement of individual social cognition, social emotions and social skills. Not only that, New Zealand also expect by physical education students to pay and harvest the experience of life, understand their own ability to control culture, responsible for their own life consciousness, for the future of the initiative to create a happy life and improve their own wellbeing preparations. This encourages oneself management and enhances self-efficacy experience, which makes students more active in the face of the crisis, setbacks and difficulties when using the coping style, self, instead of complaining, evading responsibility. This positive behavior, once established, will undoubtedly benefit the students for life. The goal of independence and self-discipline can also be found in Canada and Ireland. Methods the amount of physical activity from the sports curriculum of middle school students will realize to break up the whole into parts of 30 minutes a day, and try to other aspects of this time management and allocation method to wide in life, to understand life, life goal of teaching management.

\section{THE PROMOTION OF TEENAGERS' PHYSICAL FITNESS AND HEALTH THROUGH COMPREHENSIVE DEVELOPMENT}

The state promulgated the Compulsory Education Sports and Health Curriculum Standards (2011) in China, which does the promotion of teenagers' physical fitness and health planning and guidance [5]. In the new sports curriculum standard, the overall goal and each grade sub target form an organic system together. The goal of physical education curriculum includes four aspects: sports participation, sports skills, physical health, mental health and social adaptation.

Among them, under the dimension of Sports Participation, students are required to take part in a variety of sports activities, and they are willing to participate in the new sports activities, competitions, and experience the joy and excitement. The Motor Skill includes 3 dimensions of learning sports knowledge, mastering sports skills and methods, enhancing safety awareness and prevention capabilities. The knowledge include knowledge and exercise of the Olympic movement related action name meaning and process. The skills include physical basic activity and ability to complete the sports games, to master a variety of sports activities, such as swimming or skiing activities, martial arts activities and traditional folk sports activities. In the enhanced security awareness and prevention capabilities, it is necessary to grasp the safety of sports activities, games, daily life, and take the initiative to avoid sports injuries and dangerous. The Health dimension requires students to improve the body and posture. The Basic Health Knowledge and Methods achieve the target of understanding of individual health care knowledge and methods, and to understand the disease prevention and control knowledge. Creating a good body shape and posture requires students to improve body and posture.

The Comprehensive Development Ability and Fitness Ability requires students to develop flexibility, agility, speed and strength, able to understand the physical form, through the practice of the development of flexibility, agility, speed and strength. Improve the Ability to Adapt to the Natural Environment requires students to improve their ability to adapt to climate change. The goal of Mental Health and Social Adaptation is to cultivate the strong will quality, to learn how to regulate and control emotion, to form the consciousness and ability of cooperation, and to have good sports morality. Schools arrange family sports homework. Parents support students to participate in social sports activities, and regularly carry out the sunshine sports "series of activities and walked down the network, out of the dormitory, to the playground" theme mass extracurricular physical exercise activities. Teenagers insist on carrying out an annual student winter longdistance race and other group activities, covering the school students extracurricular physical exercise system. These measures are to help young people develop sports interest, to develop a lifelong habit of physical exercise, to promote healthy lifestyles, to grasp the movement technology, to promote sports and health, to enhance the awareness of the rules, the spirit of cooperation and will quality, to promote the comprehensive development of teenagers.

With the basic completion of Basics crucial tasks, basic education has entered into the stage of connotation development in China, focusing on the scale to quality change. The majority of the people's demand for education has also changed from basic learning to good learning. The core task of education reform and development is to improve the quality of education. The quality of education should reflect the orientation of quality education, people-oriented, concerned about the overall development of people, playing a guiding role, and gradually promoting the improvement of the quality of basic education [6] 。

\section{OUTLOOK AND SUMMARY}

Although the teachers in China have taken a series of work, such as the Strengthening of Physical Education and Promote Physical and Mental Health of Students Comprehensive Development of Opinions, National Fitness Program (20162020) and Sports Development Plan Of 13th Five-Year, there are still many deficiencies and weaknesses at the beginning of practice, such as deregulation the reform of examination system, school management, teachers improve their own quality, social resources integration etc. there is still room for improvement. The future education should not take the knowledge education as single evaluation criteria, when the transition from knowledge orientation to the development orientation, to promote the comprehensive development of human beings, contribute to the training of the new century international talents. 


\section{REFERENCES}

[1] General Administration of Sport, “2014 National Physical Fitness Monitoring Bulletin, ” November,2015.

[2] Yuehui Pang, "The philosophy of man's overall development, ” Journal of Southwestern Normal University (HUMANITIES AND SOCIAL SCIENCES EDITION), pp.5-9, May,2002.

[3] State Council, “National Fitness Program (2016-2020) , ” National Development [2016] document No. 37.
[4] Planning of the State Sports General Administration, "The State Sports General Administration of sports development of 13th Five-Year, ' May,2016.

[5] State Council, "Strengthening school sports to promote the health of student's all-round development of the views, " Issued 2016 Document No. 27.

[6] Qi Dong, "Basic education quality monitoring system in Chinese characteristics, ” People’s education, pp. 2-3, February,2007. 